\title{
¿SERVIR CON LA PLUMA? EL EFECTO ESPEJO EN EL AUSTRIAS CARMEN DE JUAN LATINO
}

\author{
TO SERVE WITH THE PEN: THE MIRROR EFFECT IN \\ JUAN LATINO'S AUSTRIAS CARMEN
}

\author{
Maxim Rigaux \\ University of Chicago
}

\section{RESUMEN}

En este ensayo destaco cómo Juan Latino (ca.1518-ca.1595), antiguo esclavo de la ilustre familia Fernández de Córdoba, crea una persona literaria compleja a través de sus dos volúmenes de poesía publicadas en 1573 y 1576 en Granada. Prestaré atención especial a la manera en que Latino establece un efecto espejo en el Austrias Carmen, un poema épico de dos cantos en latín que celebra la victoria cristiana en la batalla de Lepanto. Este recurso literario le da la oportunidad de fijar la atención no solo en su mecenas Pedro de Deza, pero también en su propia figura como poeta único. Compararé las estrategias textuales de Latino con el uso del efecto espejo en Las Meninas de Diego Velázquez.

Palabras clave: Juan Latino, Literatura neolatina, Autorrepresentación, Efecto espejo, Las Meninas.

\begin{abstract}
This article highlights how Juan Latino (ca. 1518-ca. 1595), a former black slave of the illustrious Fernández de Córdoba family, creates a highly complex literary persona through the two volumes of Latin poetry he published in the 1570s in Granada. I will pay special attention to Latino's staging of a mirror effect in the Austrias Carmen, a two-book epic on the Christian victory in the battle of Lepanto. This technique enables the poet to place his patron Pedro de Deza at the centre of attention alongside his own authorial figure. In my analysis, I will compare Latino's textual strategies to Diego Velázquez's use of the mirror in Las Meninas.
\end{abstract}

Keywords: Juan Latino, Neolatin poetry, Self-fashioning, Mirror effect, Las Meninas. 


\section{RESUM \\ ¿SERVIR AMB LA PLOMA? L'EFECTE ESPILL EN EL AUSTRIAS CAR- MEN DE JUAN LATINO}

En aquest assaig destaque com Juan Latino (ca. 1518 - ca. 1595), antic esclau de la il.lustre família Fernández de Córdoba, crea un personatge literari complex a través dels seus dos volums de poesia publicats en 1573 i 1576 en Granada. Atorgaré una especial atenció a la manera en què Latino estableix un efecte espill en el Austrias Carmen, un poema èpic de dos cants en llatí que celebra la victòria cristiana en la batalla de Lepant. Aquest recurs literari li permet de fixar l'atenció no sols en el seu mecenes Pedro de Deza, sinó també en la seua pròpia figura com a poeta únic. Compararé les estratègies textuals de Latino amb la utilització de l'efecte espill a Les Menines de Diego Velázquez.

Paraules clau: Juan Latino, literatura neollatina, autorepresentació, efecte espill, Les Menines. 
Juan Latino, antiguo esclavo del tercer duque de Sessa, nos asegura en sus dos volúmenes de poesía, publicados en Granada respectivamente en los años 1573 y 1576, que Pedro de Deza, presidente de la Real Audiencia y Chancillería de Granada, le encargó escribir las dos obras.' Sin embargo, lo encargado por Deza -o sea, la epopeya Austrias Carmen de la primera obra y los epitafios de la segunda- se extendió con poemas adicionales que se dedican a Felipe II y a diferentes personas ilustres y relacionadas con la corte del rey, como también al propio Gonzalo Fernández de Córdoba en la segunda obra sobre el traslado de los cuerpos reales a El Escorial. Llama nuestra atención cómo Latino, poniendo a estas personas juntas en un mismo volumen de poesía, es capaz de crear una relación afectuosa entre todos ellos. Particularmente, a través del uso de la figura retórica del apóstrofe, establece una conexión fuerte entre Deza y la Casa de Austria en la primera obra. ${ }^{2}$ De este modo, Latino parece cumplir con un tópico

1 Para la biografía más reciente y completa del autor, véase MARTíN CASARES, Aurelia (2016), Juan Latino: talento y destino, Universidad de Granada, Granada. Sobre el contexto histórico y social de la Granada de aquella época, véanse los análisis detenidos de SÁNCHEZ MARTíN, José Antonio y MUÑOZ MARTíN, María Nieves (2009), "El Maestro Juan Latino en la Granada renacentista. Su ciudad, su vida, sus protectores", Florentia Illiberritana, n² 20, pp. 227 260, y WRIGHT, Elizabeth (2016), The Epic of Juan Latino. Dilemmas of Race and Religion in Renaissance Spain. University of Toronto Press, Toronto, pp. 21-83.

2 RIGAUX, Maxim (2016), "Casting the Reader as Eyewitness: Apostrophe and Visualization in Juan Latino's Austrias Carmen (1573)", Hispanic Review, Pennsylvania, n 84/4, pp. 405 425. En este artículo se examina cómo el uso recurrente del apóstrofe a Pedro de Deza no solo aumenta el efecto de visualización de lo narrado, sino también establece una relación afectuosa entre Deza y el héroe-protagonista Don Juan de Austria. 
recurrente en los prefacios de la poesía épica hispánica: el de servir "con la pluma". ${ }^{3}$ En este artículo, profundizaré el análisis del uso de esta estrategia literaria que le sirve al narrador para fijar la atención en Deza. Mi hipótesis es que Latino provoca con esta figura retórica un efecto espejo en su Austrias Carmen que se puede comparar con lo que ocasiona Diego Velázquez en Las Meninas por medio de la representación de un espejo al fondo de la tela con la imagen un poco borrosa de los reyes españoles. Concretamente, demostraré que este efecto espejo se manifiesta especialmente en un episodio clave del poema épico donde el héroe-protagonista Don Juan interpreta las palabras de Deza en un discurso hacia los capitanes de la Santa Liga después de la victoria en la batalla de Lepanto 7 de octubre de 1571).

Tal y como Velázquez se representa de manera enfática a sí mismo en Las Meninas, es evidente que Latino se auto-promociona continuamente en su obra literaria. El apóstrofe en el poema épico es tan solo una de las muchas estrategias utilizadas por el poeta para recalcar su propia figura. Aunque los dos libros se arraigan fuertemente en un contexto local -el de las festividades y ceremonias en la Granada de los años setenta del siglo XVI- por lo que la poesía tiene un objetivo claramente celebrativo y al servicio de la Monarquía Hispánica, no cabe duda de que el verdadero motivo de Latino era su propia promoción como el poeta ideal de Felipe II. Así, además de una cubierta con el escudo real que está rodeado de epígrafes en latín, las dos obras tienen un frontispicio con dedicatoria principal al Católico Rey Felipe (Ad Catholicum Philippum). Más aun, la primera parte del volumen de 1573 se distingue por los dos poemas dirigidos directamente a Felipe II. Aparte del poema épico, éstos son los poemas que han recibido la mayor atención de la crítica moderna. ${ }^{4}$ El primer poema, una elegía de 78 versos, - 36 dísticos, se destaca por la autorrepresentación -o self-fashioning-del poeta como etíope cristiano. El segundo, un epigrama de 20 versos, o 10 dísticos, ha sido interpretado por Christopher Maurer como la inspiración

3 Para una discusión de este tópico en muchos de los prólogos de la poesía épica hispánica, véase VEGA, María José (2010), "Idea de la épica en la España del Quinientos", en VEGA, María José y VILÀ, Lara (coords.), La teoría de la épica en el siglo XVI (España, Francia, Italia y Portugal), Editorial Academia del Hispanismo,Vigo, pp. 115-131.

Véanse FRA-MOLINERO, Baltasar (2005), "Juan Latino and His Racial Difference.", en EARLE, Thomas F. y LOWE Kate. J. P. (coords.), Black Africans in Renaissance Europe, Cambridge University Press, Nueva York, pp. 326-344; MAURER, Christopher (1993), "Un monarca, un imperio y una espada: Juan Latino y el soneto de Hernando de Acuña sobre Lepanto", Hispanic Review, Pennsylvania, ${ }^{\circ} 61 / 1$, pp. 35-51; y WRIGHT, The Epic of Juan Latino, pp. 97-112. 
fundamental de un soneto afamado en España por su conexión con el régimen franquista: el soneto de Hernando de Acuña con el verso célebre "Un monarca, un imperio y una espada". ${ }^{5}$

En el primer poema, la elegía, Latino destaca su ambición literaria, presentándose como el poeta único de la Casa de Austria y comparándose explícitamente con Don Juan de Austria, el triunfador único en la historia. Además, desde el inicio del poema, destaca su color negro e identidad de etíope cristiano como un aspecto llamativo e incluso exótico. Relaciona su propia singularidad como poeta etíope con la de Don Juan como vencedor del imperio Otomano. Su autorrepresentación como etíope y negro no es gratuita en absoluto, sino muy bien pensada. ${ }^{6}$ Elaborando una inversión irónica de la narrativa bíblica del bautizo del eunuco etíope de la reina Candace por el apóstol Felipe, Latino trata de convencer al rey Felipe de que su propia existencia es como un don divino que no puede rechazar:

Non temere Aethiopi coelo datus ergo Philippus, Ne Aethiopi iusta haec forte Philippe neges.

No por casualidad al etíope fue ofrecido por el cielo Felipe; así, no niegue sin más a este etíope lo que merece, Felipe. ${ }^{7}$

Así como el encuentro entre el eunuco etíope, tesorero de la reina Candace, y el apóstol Felipe no es casual, tampoco es accidental el del rey Felipe II con el poeta etíope Latino. Después, Latino alude también a la idea de

5 MAURER, "Un monarca, un imperio y una espada". Sin embargo, esta interpretación, a mi modo de ver, ha vuelto a estar puesto en tela de juicio recientemente. Véase el artículo de DíEZ FERNANDO, José Ignacio (2011), "La inspirada poética del soneto Al rey, nuestro señor, de Hernando de Acuña", Hispanic Review, n 79/4, pp. 527-546.

6 En su análisis detenido de esta elegía, Baltasar Fra-Molinero destaca la importancia de esta identificación de Latino con la Etiopía bíblica. La considera como una estrategia retórica por la cual Latino se quiere distinguir categóricamente del grupo étnico de los moriscos. Véase FRA-MOLINERO, "Juan Latino and His Racial Difference, pp. 336-338.

7 Juan LATINO, Ad Catholicum, fol. 10r. Traducción mía. Siempre cito del ejemplar original del primer volumen que se encuentra hoy en día en la Biblioteca Universitaria de Granada, CJC_86; salvo en el caso de la epopeya, por la cual utilizo la edición y traducción de José Antonio SÁNCHEZ MARÍN: véase infra n. 12. 
que siempre ha sido una costumbre de reyes (mos regum) tener elementos exóticos en sus palacios. Todo ello, por supuesto, sirve para inmortalizar al rey y su dinastía.

Latino no solo se representa como el nuevo poeta de Felipe II, sino que también resalta su relación con su mecenas local, Pedro de Deza, el que da cierta coherencia a la obra entera. Después de varios poemas laudatorios ajenos que sirven para aumentar la autoridad del poeta, Latino presenta un primer epigrama de su propia mano (de catorce versos y dirigido al lector): se trata de una breve descripción de introducción a la persona Deza. El epigrama preliminar sirve como prueba del enorme cariño que siente Deza por la Casa de Austria. El último dístico le caracteriza como un confidente del rey (fidus regis):

Nam fidus regis meditatur grandia: princeps

Floreat, et frater carmine doctiloquo.

Porque un confidente del rey medita sobre cosas grandes:

que florezcan el príncipe y su hermano por la elocuente poesía. ${ }^{8}$

Sin embargo, el 'fidus regis' puede referirse tanto al mecenas Deza como al poeta Latino que escribió la poesía de este volumen. Es imprescindible observar, ya aquí en este primer poema, cómo Latino hace hincapié en su propio papel decisivo para revelar los servicios reales de su mecenas.

Vuelve la figura de Deza al final de la primera parte del volumen de 1573. Se trata de un poema en el que Latino se dirige directamente a su mecenas. Anticipa el tono dialógico del siguiente poema épico, que se caracteriza por el uso frecuente del apóstrofe. Aquí el poeta le ofrece a Deza el poema encargado de una manera fuertemente visual:

Ecce tibi Austriades prodit iam, Deza, legendus, qui victor pelagi dicitur esse ducum.

¡Mira! Ya te aparece, Deza, a tí, para ser leído, el Austríades, el que, según se dice, es el triunfador de los capitanes en el mar. ${ }^{9}$

8 Juan LATINO, Ad Catholicum, fol. 5 r.

9 Juan LATINO, Ad Catholicum, fol. 44v. 
Esta visualización se puede entender de diferentes maneras. Primero, por la disposición de los folios en el volumen, Latino alude al nuevo frontispicio con el escudo de armas de la familia Deza y con el nuevo título que anuncia el Austrias Carmen. De esta manera, la visualización se hace concreta cuando se refiere a la materialidad del libro mismo. Segundo, el "Austríades" es una clara alusión al héroe del poema, Don Juan, quien aparece ante los ojos del lector como en el teatro. El verbo 'prodire' tiene aquí el doble sentido de 'pasar adelante' $y$ 'salir a escena'. La idea del poema épico como la lectura de una obra teatral o, aún más, de una representación literaria de una batalla ficticia que formara parte de las festividades en Granada nos hace comprender mejor las estrategias literarias de Latino. Latino destaca la figura de su mecenas a lo largo de todo el poema épico a través de un exordio extenso y un uso recurrente del apóstrofe a Deza. Estas interrupciones de la narrativa sirven para motivar a Deza, en particular, y al lector, en general, a imaginarse la descripción visual del poeta. Estos momentos de interrupción ocurren sobre todo cuando el autor describe episodios de fuerte emoción o dramatismo, como la primera aparición de Alí Bajá, el enemigo turco, o la violencia durante la batalla naval. Elizabeth Wright ha interpretado estos episodios de manera subversiva: como una crítica (casi enigmática) del poeta contra su mecenas por la actuación implacable de éste hacia los moriscos durante la Guerra de las Alpujarras. ${ }^{10}$ En esta guerra civil, se le atribuye en gran parte al presidente de la Real Chancillería Pedro de Deza la rebelión de los moriscos, por su "manera de proceder [...] con esta gente," según las palabras del propio Don Juan de Austria en una carta a su hermano Felipe II. ${ }^{11} \mathrm{Es}$, pues, muy probable que Deza le encargara a Latino este poema sobre la victoria de Don Juan en la batalla naval de Lepanto contra el Imperio Otomano como una manera de mejorar su imagen y de hacer auto-propaganda.

El apóstrofe resalta el interés de Deza no solo por la Casa de Austria, sino también por la fortuna de los moriscos. Así, se puede entender mejor el episodio más curioso de la epopeya, es decir, la escena en la cual Don Juan pronuncia un largo discurso a los capitanes destacados de la Santa Liga. Después de haber observado algunas de las acciones más crueles de toda la batalla, Don Juan empieza a anticipar la reacción futura de Pedro de

10 Véase, sobre todo, WRIGHT, Elizabeth (2009), "Narrating the Ineffable Lepanto: The Austrias Carmen of Joannes Latinus (Juan Latino)", Hispanic Review, Pennsylvania, n 77/1, pp. 71-92, en particular pp. 76-77.

11 En CARO BAROJA, Julio (2000 [1976]), Los moriscos del Reino de Granada. Ensayo de historia social. Istmo, Madrid, p. 157. 
Deza cuando escuche éste la noticia de la victoria de Lepanto en Granada. El poeta-narrador interrumpe el discurso, nada menos que tres veces, para hacer hincapié en las palabras de Don Juan sobre Deza:

Imprimis te, Deza, suum dum laudat amicum, quae tibi vitarit narrare pericula gestit. Ad proceres versus repetebat, Deza, subinde: 'Quid nunc noster,' ait, 'faceret, iam Deza per urbem si nunc Hispanos victores crederet unus? Obvius, ut ridens nobis occurreret ille fortunasque meas, fratris nomenque Philippi aequaret caelo, vultu acceptissimus omni.'

Al mismo tiempo que te alaba sobre todo a ti, Deza, amigo suyo, arde en deseos de narrar los peligros que te evitó; vuelto a los generales, Deza, decía a continuación: "¿Qué haría nuestro Deza ahora por la ciudad -dijo- si fuera el único en saber vencedores a los hispanos? Como riendo con su rostro tan grato a todos, saldría a nuestro encuentro, levantaría hasta el cielo mi buen hado y el nombre de mi hermano Felipe ${ }^{\prime \prime}{ }^{12}$

Se podría decir que Deza se convierte en el verdadero protagonista del poema. Lo que importa es la reacción emotiva de Deza, no solo en este momento, sino también a lo largo del poema a través de los apóstrofes recurrentes. Sin duda alguna, el clímax de este proceso es cuando don Juan imita las palabras de Deza y (casi) se identifica con él:

'Est famulus regi fidus promptusque Philippo.

Argumentum ingens mentis, quae ad regia nata est:

«Pellebam haereticos, Mahumeti et crimina sectae, scindere dum propero non iam medicabile vulnus, sinceras partes purgataque oppida peste $[\ldots]^{\prime \prime \prime}$

12 Juan LATINO, Austrias Carmen, vv. 1382-89 [Liber II]. Utilizo siempre la traducción española de SÁNCHEZ MARÍN, José Antonio (1981), La Austriada de Juan Latino. Introducción, traducción inédita y texto, Universidad de Granada, Granada, p. 143. 


\begin{abstract}
"Es un súbdito fiel y diligente para con su rey Felipe, prueba evidente de su inteligencia que nació para acciones reales: 'Yo rechazaba a los herejes y los crímenes de la fe de Mahoma, en tanto que me apresuro a separar de las partes sanas la herida ya incurable, y las ciudades purificadas de esta peste $[\ldots]^{\prime \prime} .^{13}$
\end{abstract}

Cuando Deza como lector primero y principal del poema épico lee estas últimas palabras, lee, en realidad, su propio discurso y se ve a sí mismo reflejado. Este efecto espejo es similar a lo que ocurre, por ejemplo, en Las Meninas de Diego Velázquez. El comitente de la pintura, el rey Felipe IV, se ve a sí mismo y a la reina consorte, Mariana de Austria, en el espejo que está al fondo de la pintura. Sin embargo, el retrato de los reyes ocupa un lugar central, a la misma altura de los ojos del espectador. De la misma manera, Deza se ve a sí mismo en un momento clave, como el de la repetición de sus propias palabras por el héroe-protagonista, sin olvidarse de todos los apóstrofes a lo largo del poema, que tienen -en retrospectiva- un efecto similar.

El poema épico de Latino trata en primer lugar de la reacción visual y emotiva del lector a los versos del poeta. Muchas de las descripciones son ambiguas y dejan la interpretación del lector abierta. De la misma manera, se ha observado que uno de los atractivos más fuertes del cuadro de Velázquez es su ambigüedad interpretativa, la cual se debe en gran medida al hecho de que el punto de la mirada del espectador sea variable y-por consecuencia- también lo es la interpretación de la pintura. ${ }^{14}$ Cada interpretación depende de la perspectiva del espectador que asume el papel más importante en el cuadro. En el poema de Latino es el lector quien asume el papel más importante. De hecho, a través del uso recurrente del apóstrofe, el lector es alentado a que visualice la descripción verbal del narrador y medite sobre lo que ve con el ojo de la mente. Al mismo tiempo, según la retórica clásica, este estado de enargeia convida también a la admiración del ingenio del poeta-orador. ${ }^{15}$ En efecto, el hecho de que el lector admire

13 Juan LATINO, Austrias Carmen, vv. 1394-98 [Liber II], p. 143.

14 La bibliografía entorno a esta pintura es casi infinita. Me limito aquí a referir a la obra de BROWN, Jonathan y en particular a su Velázquez: Painter and Courtier,Yale University Press, New Haven, 1986. Además, quiero destacar las reflexiones sobre Las Meninas como una meta-metaimagen en MITCHELL, William J. T. (1994), Picture Theory: Essays on Verbal and Visual Representation. The University of Chicago,Chicago \& London, pp. 58-64.

15 Por ejemplo, QUINTILIANO dice en sus Instituciones Oratorias que a través de la enargeia uno es capaz de tener ante sus ojos la imagen inicial del poeta-orador. Véase PLETT, Heinrich F. 
la situación descrita se debe a la mano del escritor quien puso no solo su mecenas en el centro de la atención -si bien en el espejo al fondo,- sino también su propia figura y su manera ingeniosa de retratar las cosas.

La ambigüedad de la interpretación es particularmente fuerte en las representaciones del remero morisco y del capitán turco Alí Baja. Aquí, el narrador intenta arrancarle al lector, en primer lugar Deza, una reacción emotiva y luego interpretativa de la descripción. En segundo lugar, cada lector está invitado a reflexionar sobre su propia reacción a la imagen lastimosa del Otro y a juzgar la actitud de Deza contra los moriscos. Deza, el primer lector y así también testigo del procedimiento de escritura del poeta, se convierte en otro objeto representado. Por eso, el presidente Deza -formando parte del espectáculo implícito que crea el narrador, primero, a través de la imaginación de Don Juan y, segundo, para los demás lectores que lean las escenas caracterizadas por el apóstrofe de una manera diferente-acapara toda la atención. La pregunta que procede automáticamente de estas observaciones es -lógicamente- la siguiente: j̇cuál es la imagen que se tiene de Deza después de leer el poema épico?

La respuesta a esta pregunta es compleja ya que el poema es deliberadamente ambiguo. Véamos el ejemplo más significante del primer libro de la epopeya: la representación -rara en los poemas de Lepanto- de un remero morisco de la Santa Liga. No cabe ninguna duda de que el poeta quiere provocarle al lector una reacción emotiva por medio del episodio fuertemente visual. Antes de dirigir la atención a un remero morisco individual, Latino le presenta a Deza la importancia de los remeros para el éxito de la Liga: "Éste es el mérito esencial de la flota, ésta es su fuerza, su poderío, Deza". ${ }^{16}$ Luego, el poeta-narrador describe que un cierto capitán cristiano le mete miedo al remero morisco, quien está observando, entre temor y esperanza, a sus amigos turcos en el otro campo. El lenguaje amenazante del capitán anónimo hacia uno de los remeros moriscos nos hace compartir los sentimientos de miedo de un morisco cautivo. La última imagen que Latino pinta de él nos hace comprender su victimización:

Impellens dulcis patriae reminiscitur agros, cui mors aut summo libertas danda periclo.

(2012), Enargeia in Classical Antiquity and the Early Modern Age: The Aesthetics of Evidence, Brill, Leiden, pp. 7-21.

16 Juan LATINO, Austrias Carmen, v. 386: "Haec classis virtus, haec vis, haec, Deza, potestas". El énfasis es mío. Nótese la triple repetición en el original latín del pronombre deíctico 'haec'. 
Mientras rema, recuerda los campos de su amada patria, quien ha de alcanzar la muerte o la libertad a cambio del mayor peligro. ${ }^{17}$

Esta imagen del morisco recordando su patria alude a una imagen similar que se encuentra en el modelo principal de Latino, la Eneida de Virgilio.

De hecho, en el décimo libro de su epopeya, Virgilio representa una imagen dolorosa de Antores, una figura secundaria que aparece una sola vez en todo el poema. ${ }^{18}$ Es llamativo por varias razones. Primero, el poeta deplora la muerte de un compañero de Evandro, rey de los arcadios. Antores, antiguo compañero de Hércules, se unió a Evandro después de haberse marchado de Argos. Se observa que murió, desgraciadamente, herido por una lanza dirigida hacia otra persona. ${ }^{19}$ La lanza que mató a Antores vino de la mano de Mezencio, quien quería arduamente vengarse de Eneas por la muerte de su hijo Lauso. En otras palabras, esta alusión a la muerte de Antores sugiere que se debería interpretar de una manera similar la muerte del remero morisco durante la batalla naval. El morisco se ha convertido en una víctima indefensa e inocente. Segundo, la frase a la que alude Latino es, precisamente, la que utiliza Quintiliano como ejemplo acertado en su discusión de enargeia. Quintiliano sostiene que el poeta romano tenía ante el ojo de la mente una imagen de la muerte. ${ }^{20}$ Tercero, esta alusión en un episodio caracterizado por el apóstrofe y la fuerte visualización revela muy bien el arte poético de Latino. Demuestra cómo el poema épico es una representación de una representación clásica a la que señala por medio del uso del apóstrofe. El Austrias Carmen es un meta-metapoema, o sea, el equivalente verbal de la práctica visual de Velázquez's Las Meninas.

Además de la función metapoética de este y otros episodios similares en el poema, no se puede negar que el efecto espejo estimula también al lector a hacer una autorreflexión. Existe quizás la tentación de interpretar la representación compasiva del remero morisco como un elemento de crítica en el texto. Sin embargo, me parece poco probable que un erudito y futuro cardenal como Pedro de Deza, quien estudió derecho en el Colegio Viejo de San Bartolomé de Salamanca y fue un verdadero mecenas de las artes, no solo en Granada, sino también más tarde durante su larga estancia en

17 Juan LATINO, Austrias Carmen, v. 417-18. He modificado ligeramente la traducción aquí, porque creo que luce más fuerte el impacto del episodio si se traduce el sujeto de la escena -el remero morisco (remex Maurus)- en el singular.

18 VIRGILIO, Eneida, X.781-82: "Caelumque / aspicit et dulcis moriens reminiscitur Argos».

19 VIRGILIO, Op. cit., X.781: "Sternitur infelix alieno vulnere". El énfasis es mío.

20 QUINTILIANO, Instituciones Oratorias, VI.II.32. También PLETT, Enargeia, pp. 179-81. 
Roma, ${ }^{21}$ no entendiera los mensajes subversivos del poeta Latino, si éste hubiera sido el caso. El hecho de que se publicaran las dos obras de Latino me parece prueba decisiva de que a Deza le agradó la poesía del poeta etíope y -por consiguiente- también la representación lastimosa del remero morisco y del capitán turco. Son imágenes que, en efecto, conmueven y estimulan a una meditación religiosa de la situación política.

No hay que olvidar tampoco que en la Historia del rebelión y castigo de los moriscos del reino de Granada (1600), una obra que se considera como la más propagandística de las tres que se han escrito sobre las guerras civiles en las Alpujarras, ${ }^{22}$ Luis del Mármol Carvajal observa frecuentemente que el presidente Deza dio muestras de compasión con los moriscos. El mejor ejemplo es la respuesta que da Deza a los moriscos después del famoso discurso de Francisco Núñez Muley, cuando éste defendió los hábitos y las prácticas socio-culturales de los moriscos como reacción a la Pragmática Sanción de 1567: "El presidente le respondió [a Núñez Muley] que todo cuanto él pudiese hacer para que los vasallos de Su Majestad no fuesen molestados lo haría". ${ }^{23}$ Asimismo, se repite una y otra vez que Felipe II no quería que se murieran los moriscos, sino que se convirtieran y fueran buenos vasallos. Deza concluye así su discurso a Núñez Muley: "Concluyó con decirle resolutamente que Su Majestad quería más fe que farda y que preciaba más salvar una alma que todo cuanto le podían dar de renta los moriscos nuevamente convertidos". ${ }^{24}$ La idea de la conversión (en vez de muerte) de estos moriscos también aparece varias veces en la obra de Latino. En la epopeya, se impone la idea sobre todo en la muerte deplorada de Alí Bajá. El narrador observa explícitamente que si no hubiera muerto, Alí Bajá, un personaje admirado por los soldados cautivos y cristianos por su virtud cristiana, se habría convertido sin ninguna duda a la fe católica. ${ }^{25}$

21 Para una breve introducción a las actividades de Deza en Roma, desde 1578 hacia su muerte en 1600, véase el libro de DANDELET, Thomas James (2001), Spanish Rome, 1500-1700. Yale University Press, New Haven, pp. 98-101 y passim.

22 Al lado de la Historia de Mármol Carvajal, existen dos otras crónicas en las que se narra la Segunda Guerra de las Alpujarras: la Guerra de Granada de Diego Hurtado de Mendoza y las Guerras Civiles de Granada de Ginés Pérez de Hita.

23 MÁRMOL CARVAJAL, Luis de (2015), Historia de rebelión y castigo de los moriscos del reino de Granada. Estudio, edición, notas e índices de Javier Castillo Fernández, Universidad de Granada, Granada, p. 130, II. 10. En cuanto a la cita, refiero primero a la página de la edición moderna y luego al libro y el capítulo según la división tradicional.

24 MÁRMOL CARVAJAL, Historia de la rebelión y castigo, p. 131, II. 10. 
No es mi intención poner en tela de juicio las consideraciones historiográficas en cuanto a la postura hostil de Deza para con los moriscos. Existen suficientes pruebas de que Deza se comportaba de forma intolerante con ellos. El mejor ejemplo lo encontramos sin duda en las palabras de Don Juan en una carta a su hermano Felipe. ${ }^{26}$ Sin embargo, rechazo la tesis de que Latino hubiera intentado reprenderle a Deza su conducta con su poema épico a través del uso del apóstrofe en los episodios más dramáticos. Dicho de otro modo, rechazo la tesis de que fuera la única interpretación posible del poema. Por esa razón, es tan imprescindible el papel del lector como el que da significado al poema. El efecto espejo tiene como primer resultado que el lector se da cuenta de su propia respuesta a ciertas descripciones y que las interpreta. Por consiguiente, es posible que Deza interpretara estas situaciones como afirmativas de su actitud justificada para con los moriscos y que le gustara el poema épico como un medio de propaganda acertado. La centralidad de Deza se confirma, además, en el primer poema después de la epopeya: una peroración según las reglas de la retórica clásica, dirigida a Deza. En este poema, Latino describe el actual estado feliz (status foelix) de Granada, gracias a los esfuerzos del presidente Deza. Sin embargo, Latino apela en su primer volumen de poesía también a otras personas cercanas al ámbito del rey. Por ejemplo, hay poemas preliminares dirigidos a Antonio Gracián de Alderete Dantisco, secretario de Felipe II, a Luis Manrique, Capellán y Limosnero Mayor de la Capilla Real, y a Diego de Espinosa, presidente del Consejo de Castilla e Inquisidor General de España. Latino seguramente tiene en mente a estas personas poderosas cuando expresa por medio de Don Juan el deseo de que ellos fueran testigos de la batalla naval: "él como general deseaba que todos estuvieran presentes, los jefes hispanos, los grandes y poderosos del reino, para que Espinosa, cabeza de los pueblos en el reino de su hermano, y el Consejo Real contemplasen sus muy ilustres hazañas" ${ }^{27}$

25 Juan LATINO, Austrias Carmen, vv. 1207-13 [Liber II], pp. 130, y en particular versos 1207. 08: "Y si por azar hubiese sido capturado vivo en el combate, hubiese bebido la fe de Cristo a causa de su extraordinaria virtud." Se repite esta idea también frecuentemente en la segunda obra de Latino, De Augusta translatione. Granada: Hugo de Mena, 1576. Véase, por ejemplo, el siguiente comentario que se puede leer en una nota marginal del folio $28 \mathrm{v}$. (como parte de la primera elegía dirigida a Don Gonzalo Fernández de Córdoba): "Philippus nec Maurorum, nec Turcarum nec ludaeorum mortem desiderat, sed ut convertantur, et vivant".

26 Véase más arriba la nota 11.

27 Juan LATINO, Austrias Carmen, vv. 1374-80 [Liber II], pp. 141-43. El énfasis es mío. 
Para terminar, quiero ilustrar otro ejemplo de esta estrategia literaria a través de la cual Latino relaciona su servicio con el de ilustres personas cercanas al rey. Esta vez es un ejemplo del segundo volumen de 1576, en el que Latino conmemora el traslado de los cuerpos reales de la Capilla Real de Granada a El Escorial de Felipe II en el invierno de 1573-1574. En este libro, lleno de epitafios, incluye también dos elegías dirigidas a su antiguo maestro Gonzalo Fernández de Córdoba. En la primera, Latino hace una descripción elegante tanto del traslado de los cuerpos reales como de la 'querella' de la Granada personificada. ${ }^{28}$ Lo que me interesa destacar ahora es la manera en que Latino relaciona este traslado real con el que realizó Don Gonzalo en los años 1550, cuando éste trasladó, desde Italia a España, los cuerpos difuntos de sus padres, los segundos duques de Sessa. Según la nota al margen de este poema, la decisión de Felipe II para trasladar a varios miembros de su familia ennobleció (nobilitavit) también al tercer duque de Sessa. Latino le sirve a su antiguo dueño inmortalizando y conectando estos dos traslados 'con su pluma'. Como Deza en el poema épico, el duque de Sessa recibe toda la atención apareciendo al inicio de esta elegía sobre el traslado de los cuerpos reales. En el caso de Deza, es Don Juan quien ilustra a la persona del mecenas, mientras que en el caso de Don Gonzalo es el propio Felipe II quien ennoblece al antiguo dueño de Latino. Pero, al fin y al cabo, el lector se asombra, más que nada, del ingenio del poeta, quien sabe unir los nobles con la Casa de Austria en una relación afectuosa.

En conclusión, hemos visto cómo Latino consigue emplear un lenguaje de servicio para invertir los papeles y recalcar su propio talento como poeta ingenioso. En la epopeya, Latino celebra la victoria de la Casa de Austria en la batalla de Lepanto y sabe vincular su mecenas Deza al héroe don Juan en una relación afectuosa. Aún más, consigue centrar toda la atención en Deza a través de un uso recurrente del apóstrofe. Latino, pues, sirve en la primera obra sobre todo los intereses de su mecenas y en la segunda -aunque en menor grado- también los de su antiguo dueño Don Gonzalo. Al mismo tiempo, el servir con la pluma no significa que Latino no haga resaltar su propia persona. Lo hace, como hemos visto, explícitamente en la elegía preliminar dedicada a Felipe Il y también -aunque a primera vista de forma mucho más implícita- en el poema épico, donde a través del efecto espejo destaca su labor e ingenio, así como hace Velázquez en su

28 Sobre la figura retórica de prosopopoeia y la figura de Granada en el volumen de 1576, véase RIGAUX, Maxim (2018), "Prosopopoeia in the Funeral Poetry of Juan Latino", eHumanista: Journal of Iberian Studies, $n^{\circ} 39$, pp. 248-260. 
autorretrato en Las Meninas. El carácter fuertemente metapoético del poema épico se intensifica sobre todo en las escenas más dramáticas donde se utiliza no pocas veces el apóstrofe a Deza. Esta estrategia retórica y literaria lleva a la característica ambigüedad del poema en cuanto a cómo interpretar las escenas dramáticas, porque deja la interpretación de éstas abierta y en manos del lector. El lector, pues, asume el papel más importante en el poema épico de Latino, similar al papel del espectador en la pintura de Velázquez. Por desgracia, ya no podemos saber las respuestas de Deza y Felipe II durante su lectura de los libros de Latino, y en especial del Austrias Carmen, pero el hecho de que se publicaran parece indicar que les agradaron a los dos. 